\title{
Research on Social Governance Innovation of Shared Bikes
}

\author{
Xu Hanlei, Liu Xi* \\ School of Economics and Management, Harbin Engineering University \\ Harbin 150001, China \\ xuhanlei@hotmail.com
}

\begin{abstract}
Shared bikes have developed rapidly in recent years. Apart from their advantages of bringing convenience to people and activating social idle resources, there are also problems such as bicycle delivery, economic supervision, and bicycle use and parking. Behind it are deep-rooted government supervision, corporate operations, and some social public and other reasons. Firstly the paper introduces the connotation and characteristics of shared bikes, and then analyzes the problems existing in shared bikes. Finally, the paper proposes to coordinate and promote the government, bike enterprises, social organizations and the public to participate in the development of the shared bike industry under the concept of social governance, and puts forward suggestions to build a new shared bike governance model that integrates government, enterprises and the public. Through this mode of governance, we can promote the healthy development of the shared bikes industry and create a harmonious, stable and orderly social environment.
\end{abstract}

Keywords-Shared bikes; Shared bikes management; Social governance; Multiple subject governance

\section{INTRODUCTION}

In recent years, in line with the "sharing" development, "Internet +" concept, shared bikes rapid development, has become the focus of economic and social life. This paper will focus on understanding the outstanding problems in the development of shared bikes, deeply analyze the causes of the problems, and use innovative social governance methods to provide practical solutions to the shared bikes problems, and provide an innovative approach to the development of the shared bikes industry and the orderly conduct of society.

\section{THE CONNOTATION AND FEATURES OF SHARED BIKES}

Shared bikes are divided into early-stage shared bikes and today's non-pile shared bikes. The main research object of this paper is the latter. According to the content of ire search's "China Shared Bikes Industry Research Report 2017", shared bikes refer to non-pile bike-sharing services provided in cities, campuses and other places. The most common mode of bike-sharing today is to use the mobile phone APP to find the location of the nearby bikes, and to unlock bikes by scanning the QR code on the bike, and the bike platform can grasp the quality and use of the bike in the background in real time. On the one hand, the development of shared bikes provides convenience for people's short distance travel, drives green and low carbon environmental protection travel, is conducive to the sharing of idle social resources, and gradually develops to the international level. On the other hand, shared bikes in the process of development is faced with problems such as random parking, uneven delivery, poor management and so on, which has brought some problems to the governance of modern society.

Shared bikes have the characteristics of market and public welfare. Firstly, shared bikes are the product of the market economy and are emerging during the development of the market economy. Its producers and users are the main body of the market. Their operation is carried out under the law of the market economy. Similarly, shared bikes have public welfare, they meet the travel needs of most members of society, they are the most basic livelihood products and are a social nature. Shared bicycles are used as a carrier for public services, and they are provided by market-based means, are a mixture of public goods [1]. Defining the attributes of a shared bike in this way is, on the one hand, an affirmation of the legitimacy and public nature of shared bicycles, our attitude towards it should be encouragement and support. On the other hand, for its publicity, it is not a purely for-profit market behavior. In its application process must be both public and public welfare, so it is necessary to construct and innovate a new model of shared bike governance which is integrated with government, enterprise and people.

\section{SEVERE PROBLEMS AND CAUSES OF SHARED BIKES DEVELOPMENT}

The travel experience of passengers is affected by three stages. According to the influence from the largest to the smallest, the following stages are: riding, issuing orders, and paying stage; the key value creation factors in each stage are: vehicle condition, citizen behavior, communication and dialogue, participation behavior, mutuality, information sharing and transparency [2]. From these perspectives, we analyze the outstanding problems in the current development of shared bikes.

*The liberal arts support plan (HEUCFW180916). "Research on energy management model based on economy". 


\section{A. Shared Bikes Delivery Problems}

On the one hand, in the shared bikes industry, the companies OFO and Mobike have obtained a large amount of capital financing. Compared with other companies, they are relatively strong and account for about $80 \%$ of the market share. And the number of shared bikes put by these two companies is huge, far from other companies. On the other hand, the major shared bikes companies mainly focus their market development on the first-tier cities and the second-tier cities such as Nanjing and Hangzhou. The number of shared bikes in these cities is extremely large, and some communities and regions even seriously exceed the needs of customers, exceeds the range of local transportation, and puts tremendous pressure on the city's traffic and parking areas. It not only fails to facilitate people's travel, but too many zombie vehicles have even become the scar of the city. However, in the third and fourth tier cities, the number of shared bikes is seriously insufficient, and the supply is seriously less than the demand. It is often the case that users cannot find the shared bikes with their mobile phones, which cannot meet people's convenience requirements. The differences between the number of shared bikes and the number of permanent residents are shown in Table 1. (First-tier cities use Beijing as an example, second-tier cities use Hangzhou as an example, and third and fourth tier cities uses Dazhou as an example.)

TABLE I. COMPARISION BETWEEN THE NuMBER OF SHARED BIKES DELIVERED IN A CITY AND THE NUMBER OF PERMANENT RESIDENTS

\begin{tabular}{|c|c|c|}
\hline City & $\begin{array}{c}\text { Number of Shared Bikes (ten } \\
\text { thousand) }\end{array}$ & $\begin{array}{c}\text { Number of Permanent } \\
\text { Residents (ten thousand) }\end{array}$ \\
\hline Beijing & 235 & 2170.7 \\
\hline Hangzhou & 42 & 946.8 \\
\hline Dazhou & 0.15 & 559.8 \\
\hline
\end{tabular}

As can be seen from Table 1, according to the industry's professionals, it is more appropriate to have a shared bike for every 50 people in the permanent population, and the more appropriate number of shared bikes in Beijing is only 434000. It is far less than the actual amount put today. Therefore, the number of shared bikes in Beijing has been severely oversaturated, and the number of shared bikes that the public needs is far less than the supply of shared bikes. The situation in Hangzhou is similar to that in Beijing. According to calculations, the suitable number of shared bikes in Hangzhou is 189000 , which is lower than the current actual number and it has reached saturation. According to the current resident population of Dazhou, the number of shared bikes needed should be 112000 , and the actual investment amount is only 1500 , the supply is far from meeting public needs.

\section{B. Economic Regulation Issues of Shared Bikes}

In terms of the regulation of shared bikes deposits, China already has a large number of shared bikes users. When using bicycles, deposits are required to be paid. As shown in Table 2, different types of shared bikes have different deposits, which will generate a huge amount of liquidity. Supervision of this part has not yet been effectively implemented. Once companies have accidents, such as capital chain breakage, the user's deposit cannot be returned or cannot be returned in time, will cause social turmoil and chaos. Xiaoming bike is the best case. Enterprises are diverting deposits for additional investment, and the obtained capital financing is one of the driving forces for the expansion of many bike companies, then the issue of the ownership of the proceeds from the use of deposits for investment has not yet formed a consensus in the legal community. And the deposit paid by bicycle users is not the transfer of ownership, and no one has reached a consensus on who owns the proceeds. The country has not yet introduced a unified legal provision. The entry threshold for shared bikes is relatively low, and a large amount of social idle capital flows into the industry have put tremendous pressure on the healthy development of the industry and financial regulation. In addition, people with impure motives will illegally raise funds because of the huge temptation of the "fund pool." This will likely affect the financial order and cause harm to society.

\section{TABLE II. DEPOSIT OF DIFFERENT SHARED BIKES}

\begin{tabular}{|c|c|c|}
\hline Bike Type & Deposit & Registered User \\
\hline OFO & $¥ 199$ & 200 million \\
\hline Mobike & $¥ 299$ & 200 million \\
\hline Hellobike & $¥ 199$ & 100 million \\
\hline
\end{tabular}

In terms of the regulation of shared bikes capital, by the end of 2017, there were more than 30 shared bike platforms in China, including OFO, Mobike, Hellobike, Baicycle, CC bike, Xiaoming bike, Kuqi bike, U-Bicycle, and QIBEI, s-bike, etc. The industry has more than 30 capital entrants. Take Mobike as an example, in addition to ordinary investment institutions, there are also some PE institutions, such as Warburg Pincus, Hillhouse Investment, and a number of traditional industrial capital, such as FUJITEC, WELTMEISTER, etc. In addition, Tencent, DiDi, MI stand in teams Mobike and OFO [3]. The recent financing situation of Mobike, OFO and Hellobike is shown in table 3. However, in November 2017, bluegogo completely out of this capital melee because of the employees' arrears, debt payment by the foundry, and the risk that the user's deposit could not be refunded. 
TABLE III. RECENT FINANCING Form For OFO, MOBIKE AND HELlOBIKE

\begin{tabular}{|c|c|c|c|c|}
\hline & Financing Wheel & Time & $\begin{array}{l}\text { Financing Amount } \\
\text { (million) }\end{array}$ & Investor \\
\hline \multirow{4}{*}{$\mathrm{OFO}$} & $\mathrm{D}$ & 2017.03 .01 & $\$ 450$ & DST, DiDi, CITICPE, Matrix, Coatue, Atomico, Macrolink, etc. \\
\hline & D+ & 2017.04 .22 & Nearly $\$ 100$ & Ant Financial \\
\hline & $\mathrm{E}$ & 2017.07 .06 & Over $\$ 700$ & Alibaba, Hony Capital, CITICPE, DiDi, DST \\
\hline & E2-1 & 2018.03 .13 & $\$ 866$ & $\begin{array}{l}\text { Alibaba, Haofeng Group, Tianhe, } \\
\text { Ant Financial, Junli Finance }\end{array}$ \\
\hline \multirow{3}{*}{ Mobike } & $\mathrm{D}$ & 2017.01.04 & $\$ 215$ & $\begin{array}{c}\text { Tencent, Warburg Pincus, Ctrip, China Lodging Group, Sequoia, } \\
\text { Hillhouse, etc. }\end{array}$ \\
\hline & D2 & 2017.02 .20 & $\$ 100$ and above & Temasek, Hillhouse \\
\hline & $\mathrm{E}$ & 2017.06 .16 & $\$ 600$ & $\begin{array}{c}\text { Tencent, BMCOM International, ICBC International, Farallon } \\
\text { Capital, TPG, Sequoia, Hillhouse, etc. }\end{array}$ \\
\hline \multirow{3}{*}{ Hellobike } & D1 & 2017.12.04 & $\$ 350$ & $\begin{array}{l}\text { Ant Financial, WELTMEISTER, Chengwei Capital, FUJITEC, } \\
\text { etc. }\end{array}$ \\
\hline & D2 & 2017.12 .27 & $\$ 1000$ & Fosun, GGV \\
\hline & E1 & 2018.04 .13 & Nearly $\$ 700$ & Ant Financial, Fosun, etc. \\
\hline
\end{tabular}

TABLE IV. SHARED BIKE USER BEHAVIOR SELECTION

\begin{tabular}{|c|c|c|c|}
\hline \multirow{2}{*}{} & & \multicolumn{2}{|c|}{ User 2 } \\
\hline \multirow{2}{*}{ User 1 } & Civilized & 0,0 & Uncivilized \\
\cline { 2 - 4 } & Uncivilized & $1,-10$ & $-10,1$ \\
\hline
\end{tabular}

\section{Shared Bikes Usage and Parking Issues}

\section{1) Urban traffic pressure}

During the 40 years of reform and opening up, China's urban road construction has made brilliant achievements, this is also the process of rapid popularization of private cars, and the number and proportion of bikes have continued to decline. As a result, urban roads were not given enough space for bike lanes to develop in planning and construction. Therefore, with the rapid development of shared bikes promoted by capital in recent years, many people's demand for cycling has been stimulated. On the one hand, the city faces enormous traffic pressure and the bicycle lane space is small or even not, forcing shared bike users to occupy sidewalks or motorized lanes. There have been many accidents of bumping people and being hit, which have brought about extremely serious traffic hazards. In the bicycle parking space, shared bikes are designed to solve the "last mile" problem, they are an important tool for connecting subways, bus stations to homes or companies, but there is not enough space for bikes at the bus stations or subway stations. This led to the accumulation of bikes at the above locations.

\section{2) User uncivilized behavior}

Firstly, some users parked their bikes arbitrarily in the residential quarters or institutions, on both sides of the road, and in the middle of urban green belts for their own riding or recreational purposes. This caused a lot of residents to be dissatisfied, and arbitrarily parked bikes became a more prominent problem. Secondly, there have been many cases of destruction of shared bikes across the country. Many bike seats have been prized, baskets have been stolen, QR codes have been smeared, and bikes "on trees and lakes" have repeatedly occurred. As a result, the failure rate of shared bike increases sharply in the initial stage of expansion, and the cost of maintenance and recovery is high. Thirdly, users have shared bikes for their own. Some users hide shared bikes in a place they find only for their own convenience. Some even directly lock the bike to prevent others from using it, and convert the shared bike into a private bike, causing people's strong resentment. Regarding what kind of resources are wasted by the user's uncivilized behavior, some researchers have given explanations based on the game theory.

Li Ying pointed out that when there is only one body of shared bike user in the market, his behavior game is shown in Table 4 [4]. When user 2 chooses civilization, user 1 chooses uncivilized gains over civilized gains, so he will choose uncivilized; when user 2 chooses to be uncivilized, user 1 will still choose uncivilized (uncivilized : $-5>$ civilized : -10 ); However, when the regulation exists and its probability is greater than the ratio of proceeds to penalty, users will not default. So fines for users who breach the contract are necessary.

Big data technology has brought positive changes to human society, but also caused information alienation, data rights, information privacy, digital divide and other network information ethics issues [5]. Some scammers replace the QR code on the shared bike with the QR code downloaded by various software. Once the user scans, it will passively download various malwares, Trojan horses and so on, which will easily lead to the loss of user information. Some computer hackers have hacked into the shared bike platform and stolen a large number of personal information for profit, which has become one of the major hidden dangers. Some bikes failed after many times of use and failed to recover and maintain them in time, causing users to cause injuries during use. It is worth mentioning that minors use bikes. On March 26, 2017, a boy under 12 years old in Shanghai collided with a bus while 
riding shared bike. He used the loophole of the shared bicycle mechanical lock to use the shared bicycle without permission and violated the traffic rules, leading to tragedy. At present, China's personal Information Protection Law is still in the process of being formulated. "Cybersecurity Law of the People's Republic of China" was passed by vote at the 24th session of the 12th NPC standing Committee with the date of implementation on June 1, 2017. However, there are no unified laws and regulations to supervise the shared bike users' information and prevent the leakage of user privacy [6].
Among the numerous regulations on urban management, there are no uniform rules and regulations that fully address the regulation of shared bikes. Although many cities have introduced local regulations in response to local conditions, the lack of authoritative and uniform management regulations is a prominent problem in the regulation of shared bikes.

IV. CONSTRUCTING A NeW SHARED BIKE GOVERNANCE MODEL OF GOVERNMENT, ENTERPRISES, AND THE PUBLIC

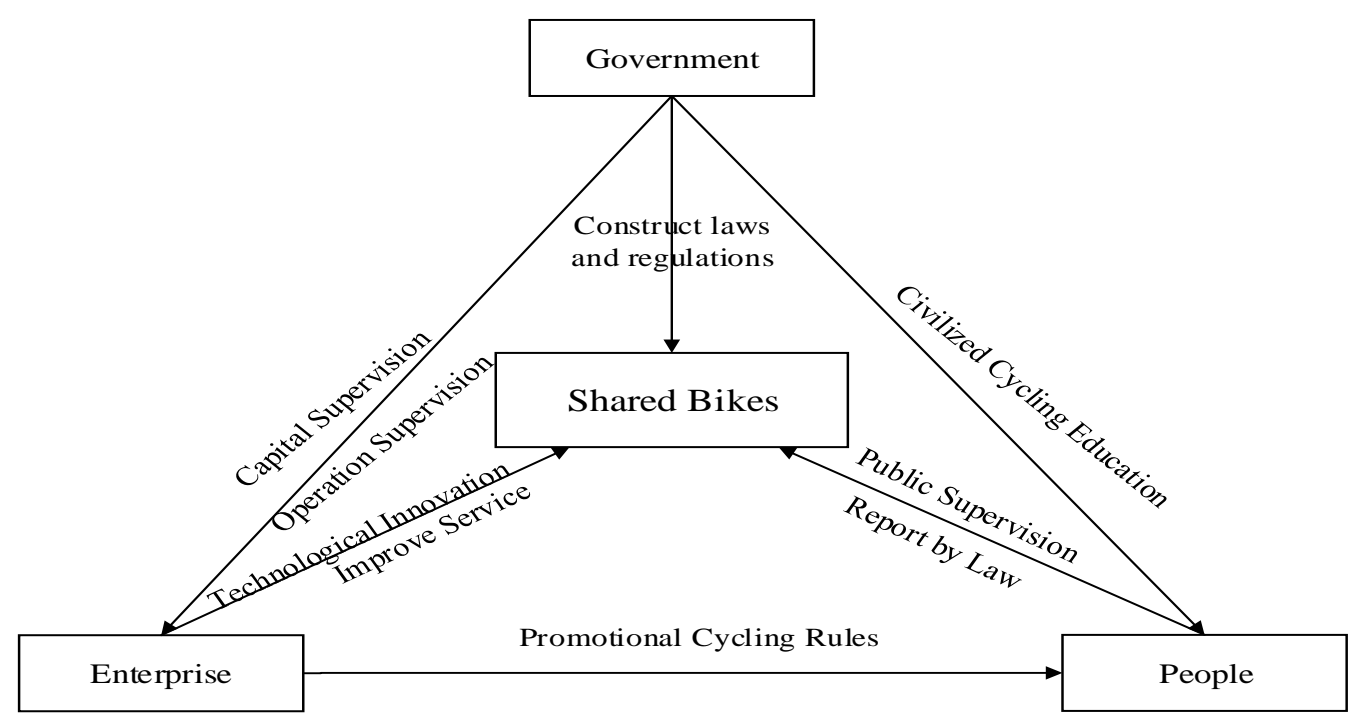

Fig. 1. The frame diagram of a new shared bike governance model consisting of government, enterprise and the public.

After the Party's 18th National Congress, social governance replaced social management and became one of the important symbols of the transformation of government functions. Social governance differs from social management in that it is a process in which the government, social groups, and the public participate in the process. It is no longer a process in which the government used only administrative orders to manage it. In the process of social governance, it emphasizes the coordination between government, social groups and the public, taking into account the interests of all parties and mobilizing all forces of society to participate in the maintenance and development of society, is therefore more democratic, effective and scientific. Similarly, shared bikes is a social nature. It is necessary to build a new type of shared bike management model consisting of the government, the enterprise, and the public. Figure 1 is a frame diagram of the new shared bike governance model integrated with government, enterprise, and people proposed by the paper.

\section{A. The Government Effectively Fulfills Supervision and Guidance Accusations}

\section{1) Supervision of capital}

The relevant government departments require companies to collect deposits for the use of shared bikes to set up special accounts, strengthen the supervision of deposits and management, and draw on the example of commercial banks paying a certain proportion of reserves to the People's Bank of China, companies reserve a certain percentage of reserves for emergency use, or introduce the third party supervision to ensure that the deposit was separated from the operating funds of the company, and a special account is opened for the deposit of the shared bikes, which is managed by the professional department to ensure the deposit security. For example, Beijing introduced a policy that a shared bike company must open a capital-specific account in the city; in order to ensure that the bike deposit can be used for special purposes, Shenzhen requires the shared bike company to set up a special account for the bike deposit and be subject to third-party supervision. 


\section{2) Strengthen the supervision of shared bike operations}

Firstly, in the aspect of improving the management regulations of shared bikes, to examine and approve the shared bike industry, improve the barriers to entry, and strengthen the review of technology, capital, reputation, etc. The government should investigate and deal with the shared bike platform which does not comply with the self-discipline standards. Once the bicycle platform is discovered to intentionally not punish users who have serious violations of the rules, the government can temporarily suspend the eligibility of the platform to continue its operation [7]; set up shared bikes parking areas, division of effective areas, to prevent the random parking of shared bikes to disrupt the appearance of the city, mobilize grassroots organizations to strengthen patrols, timely and effective penalties for illegal parking, destruction of shared bikes, and intensify crackdowns and management efforts. Secondly, in the area of supporting road traffic resources, in order to persist in planning develop public transport in priority and combine with the characteristics of each city to plan for slow traffic. "The Guidance on Encouraging and Regulating the Development of Internet Leasing Bicycles (draft for opinions)" issued by the Ministry of Transport is requested put forward the basic principle of "service-oriented, reform and innovation, standardized and orderly, territorial management, multi-party governance"; transform existing lanes, increase the area of bicycle lanes, focus on building a sufficiently reasonable bicycle lane in the upcoming road network, and the principle of the development of public transportation shall be thoroughly followed for the newly planned and constructed urban roads, and the chronic traffic planning and construction shall be completed in accordance with the specific characteristics of each city. Thirdly, clearly shared bike authorities, scientific integration of urban management, industrial and commercial approval, urban housing and construction departments, traffic management and other departmental resources and joint enforcement among departments, clarify the specific responsibilities and obligations of various departments in managing shared bikes, establish and improve the coordination mechanism of various departments, and provide an effective management mechanism for the solution of regulatory issues in the shared bikes.

3) Strengthen the construction of laws and regulations in the field of shared bikes

At present, many cities in the country have issued a number of guiding regulations regarding the operation of shared bikes and problems arising during their operation. For example, Chengdu has issued the "Chengdu's Trial Ideas on Encouraging the Development of Shared Bicycles", which has made Chengdu the first provincial capital city to introduce a shared bike management policy. In order to standardize the management of public bikes, Shanghai formulated the "Guidelines for the Development of Public Bikes in Shanghai", which played a certain role in management. However, in the case of disputes arising from bikes in legal terms, such as bumps due to brake malfunction, falls caused by wet roads, and deaths caused by primary school students riding on bikes, etc. The resulting responsibility should be borne by bike platforms, bike manufacturers, bike users or guardians, and how much responsibility they each bear, is a legal issue that needs to be addressed by the relevant authorities in the government and the legal community [8]. Therefore, it is imperative to speed up the legislative process of shared bikes.

\section{B. Enterprises Strengthen Technological Innovation and Improve Service Level}

\section{1) Strengthen technological innovation}

Enterprises should improve the guiding technology of parking area, strengthen technological innovation, set up shared bikes to park in "red circle areas", and can't pay for parking outside the area. Only bikes parked in the area can be pay to lock, to help users identify parking areas and prohibit parking areas, through this technology to regulate user parking behavior, reduce the loss caused by parking anywhere, and reduce the private use of shared bike users [9]. Enterprises should also build a user credit system through technological innovation. Through the improvement of big data and platform technologies, users will be required to record their credit history each time they ride. If the users violate rules or damages the bikes, they will be given a certain amount of punishment, which may limit their right to use bicycles. Severely refuse to refund part of the deposit or compensate by other means, and users of civilized cycling may be given appropriate discounts.

\section{2) Improve service level}

The efforts of enterprises to provide quality services and the efforts of users to use the products carefully will not only affect the quantity and cost of services during use, but also affect the quality and service life of bike products, thereby affecting the remanufacturing costs and environmental benefits of enterprises [10]. First, to ensure the quality of bikes. Enterprises should ensure the quality of shared bikes, improve the seats and bodies of shared bikes through various technologies, enhance the user's riding comfort, strengthen the quality inspection of bikes at the time of delivery, regularly maintain the shared bikes that have been used, and timely recovery and maintenance of damaged bikes to avoid inconvenience or potential safety hazards to customers due to bike damage, thereby extending the life cycle of shared bikes. Second, ensure the safety of bicycle users' information and property. The personal information of registered bike users should be kept strictly confidential, and effective rules and regulations should be established to prevent hackers from stealing information on large platforms and to strengthen the protection of big data. For the bike deposit, the enterprise should establish a sense of responsibility for integrity, set up a special account for strict management, to prevent it from entering the company's specific operations, in order to effectively guarantee the security of the deposit, without compromising the interests of bike users. 


\section{Leading the Public to Actively Participate in Bike Management}

1) Strengthen the publicity and education of civilized cycling through multiple channels and forms

Give full play to the role of grassroots self-government organizations (grassroots party organizations, residents' community committees, and enterprise employee representative committees) in conducting civilized cycling propaganda and quality education for a large number of residents and party members, strengthen the education of socialist core values. Through community activities, the distribution of effective leaflets and other traditional forms, as well as through new media such as WeChat, Weibo to strengthen the promotion of civilized cycling for large numbers of users; parents should strengthen their education for children under the age of 12. Take the tragic children in Shanghai as an example, telling them explicitly that they can't use shared bikes under the age of 12 to avoid danger; shared bike companies have to inform cycling users through various forms of innovation, such as posting pictures, making warning signs, etc., in order to guide the public to establish an honest and civilized consumption concept, not only to improve personal qualities, to comply with social morality, but also to consciously abide by various laws and regulations, not to destroy shared bikes, and not to break the law; to comply with traffic laws and regulations, not to ride bikes in violation of regulations, and consciously abide by urban management and traffic rules, compliance the bike rules, people who do not meet the age must not use shared bikes, do not park in areas where parking is prohibited or interfere with other people's traffic, do not take private bikes private, do not hide or destroy shared bikes, and be a civilized shared bike user.

2) Actively guide the public to participate in the social governance of shared bikes

Specifically, first, strengthen the supervision of illegal, uncivilized use of shared bikes. Encourage the public to report violations of bikes, illegal riding and parking of bicycles in accordance with the law and give certain rewards. Second, encourage grassroots units and units in communities to strengthen patrols and supervision, and encourage them to work with enterprises to strengthen the standardization management of shared bikes in their jurisdictions, set the bikes on time and order, fully mobilize the enthusiasm of the general public to participate, and strengthen the maintenance and construction of the city's appearance.

\section{CONCLUSION}

The emergence of shared bikes is aimed at solving the "last mile" problem. The shared bike model created in China has developed rapidly in just a few years. While bringing convenience to people's travel, it is also accompanied by the delivery, use and parking problems of bikes, government supervision issues, bike companies operating problems and the people's own problems and so on. This paper based on the connotation of shared bikes and the characteristics of market and public welfare, analyzes the problems and causes of shared bikes, and proposes related governance methods, namely the construction of a new shared bike governance model that integrates government, enterprises and people. The government strengthens supervision over capital and shared bike operations, improves and perfects relevant laws and regulations; bike companies conduct technological innovations, improve relevant technologies, and ensure the quality of bikes and the safety of user information. People accept the use of civilization propaganda and education, spontaneous mutual supervision. The birth of shared bikes as an innovation has a very strong vitality in itself, because it fits with the current economic development trend and people's travel needs. With the effective supervision of the government, the industry will certainly develop even better. At the same time, the governance of shared bike problems will directly promote the effective improvement of China's social governance and promote the healthy and orderly development of society.

\section{REFERENCES}

[1] Chu Dajian. Doing a Good Job of Shared Bikes Requires Theoretical Exploration [N]. Wen Wei Po, 2017-04-19(005). (In Chinese)

[2] Yang Xuecheng, Tu Ke. Research on the Dynamic Value Co-creation in the Sharing Economic Background: A Case Study of the Travel Platform [J]. Management Review, 2016, 28(12): 258-268. (In Chinese)

[3] Guo Peng, Lin Xiangzhi, Huang Yi, etc. Shared Bikes: Cooperative Governance in Internet Technology and Public Services [J]. Journal of Public Management, 2017, 14(03): 1-10. (In Chinese)

[4] Li Ying. Analysis of Supervision Behaviors among Different Subjects in the Shared Bike Market Based on Game Theory [J]. Modern Business, 2018(02): 164-166. (In Chinese)

[5] A Baoyang. The Governance of Network Ethics in Big Data Times [J]. Studies in Science of Science, 2015, 33(05): 641-646. (In Chinese)

[6] Zhai Yehu, Liu Tianxin. Legal Issues in Bicycle Sharing [J]. Journal of Yangzhou University (Humanities \& Social Sciences), 2017, 21(04): 3946. (In Chinese)

[7] Tan Yuan. Research on the Problem of "Bottom Line Competition" of Shared Bikes and Prevention [J]. Price: Theory \& Practice, 2017(03): 36-40. (In Chinese)

[8] Qin Zheng, Wang Qin. Synergy Mechanism in the Vision of Sharing Economy: Taking Shared Bikes for Example [J]. Reform, 2017(05): 124-134. (In Chinese)

[9] Zhu Ping, Zhu Yacheng, Dong Yuwei, etc. 2017-2018 China Shared Bike Development Report [J]. China Business \& Trade, 2017(31): 143147. (In Chinese)

[10] Liu Yuxi, Xie Jiaping. Shared-Saving Contracts for Leased Product Service System Based on Remanufacturing [J]. Chinese Journal of Management Science, 2016, 24(03): 99-108. (In Chinese) 